Linha D'Água (Online), São Paulo, v. 28, n. 2, p. 5-25, dez 2015

\title{
PLURALIDADE DOS GÊNEROS E SINGULARIDADE DO TEXTO: TENSÕES CONSTITUTIVAS DA DIDÁTICA DAS LÍNGUAS 1
}

\section{TEXTUAL GENRES AND ARGUMENTATION: PROPOSAL OF TEACHING OF OPINION PAPER IN TEXTBOOKS 2}

\section{Joaquim Dolz*}

Faculdade de Psicologia e de Ciências da Educação da Universidade de Genebra, Genebra, Suíça Myriam Abouzaid**

Universidade de Grenoble, Saint-Martin-d'Hères, França

Resumo: Esta contribuição se foca no interesse do trabalho com base em gêneros para a produção e compreensão de textos na escola. Os autores mostram a importância de trabalhar não somente os diferentes gêneros textuais e as aprendizagens específicas a eles associadas, mas também os traços familiares entre eles. A importância da avaliação dos textos em uma perspectiva genérica é abordada. Os autores também apontam a diversidade das práticas de ensino e mostram a dificuldade dos professores em articular as dimensões transversais, as convenções genéricas e a produção singular dos alunos.

Palavras-chave: didática das línguas; gêneros textuais; texto singular; compreensão oral e escrita; avaliação; produção oral e escrita.

\begin{abstract}
This contribution focuses on the language teaching on a genre-based approach through the texts comprehension and production at school. The authors show the importance of working not only the different textual genres and the specific kinds of learning associated with them, but also the parity between them. They highlight the importance of the evaluation of the texts in a generic perspective. They point out the diversity of the teaching practices and show the difficulty of the teachers when articulating the transversal dimensions, the generic conventions and the students' specific production.
\end{abstract}

Keywords: Languages Didactics, Textual Genres, Specific Text, Oral Comprehension and Production, Writing Comprehension and Production.

1 N.E.: Este texto já foi publicado em francês com o título "Pluralité des genres et singularité du texte: tensions constitutives de la didactique des langues" In: forumlecture.ch, 2015, no. 2, Université de Genève.

2 Este artigo leva em consideração os resultados de um projeto financiado pelo FNRS: "Les gestes didactiques des enseignants face aux obstacles d'apprentissage d'un genre argumentatif" (requête n¹00019_146858/1), dirigido por Joaquim Dolz.

* Professor doutor da Faculdade de Psicologia e de Ciências da Educação da Universidade de Genebra-UNIGE, Genebra, Suíça; e-mail: joaquim.dolz-mestre@unige.ch

** Professora doutora da Universidade de Grenoble, França; e-mail: myriam.abouzaid@u-grenoble3.fr 
Linha D'Água (Online), São Paulo, v. 28, n. 2, p. 5-25, dez 2015

\section{Introdução}

Nos últimos vinte anos, a abordagem pelos gêneros textuais se tornou algo inevitável na didática das línguas (Bronckart, 1996; Schneuwly, 1994; Schneuwly $\&$ Dolz, 1998), e isso, em diferentes perspectivas (Cordeiro \& Schneuwly, no prelo). O objetivo da presente contribuição é analisar os problemas que se colocam no trabalho escolar de compreensão e produção de textos de maneira a melhor compreender a pertinência da abordagem pelos gêneros. Qual o interesse da abordagem pelos gêneros? Quais as condições de uso dos gêneros textuais em situação escolar? Como organizar o ensino da diversidade do funcionamento discursivo? Como gerenciar as tensões entre os diversos gêneros a serem abordados na escola e os textos empíricos singulares que constituem a base do trabalho na sala de aula?

\section{A abordagem didática pelo gênero}

\section{Quem tem medo das folhas não deve se aproximar da floresta.} Jacques Amiot

Em uma perspectiva comunicativa, a escolha do gênero textual como unidade de trabalho se justifica por numerosas razões. Primeiramente, o gênero permite uma representação das convenções que regem uma família de textos para uma dada comunidade cultural. Assim, quando se fala de um conto maravilhoso, tanto oral como escrito, o horizonte de expectativa genérica (Jauss, 1978) deve ser, idealmente, compartilhado. Quando um professor recita em voz alta um conto de fadas para sua classe ou propõe uma roda de leitura ou um trabalho individual a partir de um álbum, os alunos aprendem a construir expectativas precisas sobre a intriga, sobre a ficção, sobre os seres sobrenaturais dotados de poderes que intervém e incarnam os personagens e sobre os objetos mágicos que conferem um caráter maravilhoso. Mesmo se o conto comporta enunciados tendo referentes próximos do cotidiano dos alunos, eles sabem que esses enunciados são projetos em um universo de ficção. $\mathrm{O}$ conto, além disso, tem diversos marcadores linguísticos que ajudam a enquadrá-lo enquanto gênero. Começar por "era uma vez" é suficiente para projetar o aluno no horizonte de expectativa do conto maravilhoso. Em se tratando de um conto de fadas moderno que parodia as fadas ou de um conto retirado do folclore oral recolhido por grandes autores como Perrault, Grimm, Aymé ou outros, trabalhar os contos com os alunos desperta essas representações comuns.

A segunda razão nos parece mais importante e ultrapassa o nível estritamente representacional. Do ponto de vista pragmático, a comunicação se realiza por 
meio de gêneros textuais. As condições e a dinâmica dos atos de comunicação são orientadas por convenções sociais determinadas. Tomemos um gênero oral como uma entrevista radiofônica: quem são os interlocutores? De qual programa eles participam? Qual é o público destinatário? Apesar da diversidade de entrevistas transmitidas pelo rádio, apesar da originalidade e criatividade dos entrevistadores e entrevistados, as condições e o contexto de realização têm em comum uma série de características e de normas restritivas que determinam a natureza do ato comunicacional: os coenunciadores são um jornalista entrevistador e um especialista entrevistado sobre um tema que mereça a interlocução; o lugar social é a mídia e o programa de rádio semanal onde se passa essa entrevista; o destinatário é o público.

Enfim, em uma perspectiva sociocultural (Vygotski, 1934/1995), os gêneros são considerados como ferramentas semióticas, cristalizando as significações associadas às práticas sociais e cuja apropriação permite a interiorização de experiências culturais sedimentadas historicamente. Os gêneros são, portanto, ferramentas semióticas que tornam possível a aprendizagem. O gênero descrição de um itinerário, por exemplo, é uma ferramenta semiótica que nos permite chegar a um lugar preciso evitando se perder. As situações de comunicação nas quais utilizamos a descrição de um itinerário (um enunciador conhece o itinerário e deseja transmiti-lo a um destinatário preciso em função de um encontro, por exemplo) são orientadas pela regulação da ação do destinatário (o deslocamento para um lugar preciso). Não é somente uma ferramenta de linguagem de mediação da ação, é também uma ferramenta cuja interiorização ajuda a pensar o próprio deslocamento. Nesse quadro (Dolz \& Schneuwly, 1998), as três dimensões da definição do gênero, proposto por Volochinov (2010/1929), nos parece importantes para mostrar o interesse didático da abordagem pelos gêneros: os conteúdos temáticos, a estrutura comunicativa e semiótica e as configuraçôes das unidades linguisticas.

\section{Três níveis para trabalhar os gêneros}

(...) o projeto discursivo do locutor, sem que este abra mão de sua individualidade e de sua subjetividade, se adapta e se ajusta ao gênero escolbido, se compóe e se desenvolve na forma do gênero dado. ${ }^{3}$ Volochinov

O ensino dos gêneros implica um trabalho com os conteúdos temáticos e esses conteúdos são dizíveis de maneira particular segundo os gêneros. Um artigo

3 N.T.: Tradução do francês proposta pelas tradutoras. 
enciclopédico sobre os vulcões seleciona informações técnicas pertinentes para compreender o fenômeno geológico. Os detalhes relativos à orogênese e a estrutura dos vulcões, a forma da cratera, a subida do magma e os materiais expelidos, a erupção, etc. fazem parte dos conteúdos particulares de referência. Se o gênero for uma narrativa mitológica sobre Vulcano, filho de Júpiter, os conteúdos temáticos seriam bem diferentes. A retomada da narrativa de Homero sobre o deus do fogo e os vulcões convocaria personagens como Júpiter e Juno, os pais de Vulcano, episódios de sua descida aos oceanos, de como foi recolhido pelas ninfas, as dificuldades de sua trajetória, etc. Os conteúdos desses dois gêneros têm apenas poucos elementos em comum entre si. Isso terá consequências no nível do trabalho de compreensão com os alunos ao longo da leitura, mas também na preparação e na seleção dos campos lexicais para a produção oral e escrita.

Os textos pertencentes a um mesmo gênero apresentam regularidades no nível da estrutura comunicativa e semiótica. Uma entrevista radiofônica, por exemplo, começa com os cumprimentos e uma apresentação do programa, do sujeito entrevistado, seguido do esquema cíclico dos turnos de fala nas trocas conversacionais "pergunta-resposta-retomada" e contém um fechamento com os rituais de despedida final. A ordem dos conteúdos temáticos se encadeia de acordo com os circuitos particulares. Frases mais ou menos conversacionais e rubricas explícitas pontuam a entrevista. Certamente, não existe apenas uma maneira de se planejar uma entrevista. Entretanto, as convenções pragmáticas regem as trocas e se impõem para organizar esses conteúdos de uma certa maneira. $\mathrm{O}$ conjunto dos signos que compõe o texto é organizado segundo as convenções e seu encadeamento contribui para a construção de significados. $\mathrm{O}$ trabalho com os alunos sobre a planificação da entrevista é, portanto, primordial para estabelecer a progressão temática e dar sentido ao conjunto da sequência textual. Esse mesmo trabalho em produção é pertinente para sustentar as operações de planificação de uma entrevista (ou de qualquer outro gênero) visando garantir a recepção pelo destinatário em função do padrão das convenções.

Os defensores da escrita criativa propõem por vezes um trabalho fora das normas genéricas. Ainda assim, a escrita singular se reporta, de uma maneira ou de outra, às normas convencionais e ao horizonte genérico que ela tenta subverter. A aprendizagem pelos gêneros, incluindo a criatividade para um determinado gênero, não saberia se situar fora de um trabalho com as operações de planificação. A organização de um gênero frequentemente implica a presença de outros tipos de discurso. Por exemplo, uma fábula pode apresentar uma parte narrativa, uma parte dialogada (discurso em situação) e uma parte argumentativa no fechamento (quase sempre sob a forma de moral), ou no interior do diálogo. É evidente que, 
do ponto de vista da organização textual, esses trechos que pertencem a diferentes tipos de discurso (Bronckart, 1996), apresentando as regularidades que Adam (2004) chama de "sequências textuais", constituem unidades composicionais do gênero que convém abordar no ensino. A intertextualidade - entendida como a presença de um texto em outro, como no caso das citações - e a paratextualidade títulos, prefácio, imagens, etc. - contribuem também para a arquitetura do gênero.

A última dimensão recobre, em um nível mais microscópico, as escolhas operadas em matéria de textualidade. A abordagem pelos gêneros permite colocar em evidência as configurações das unidades linguísticas relativas aos grupos de gêneros e, portanto, antecipar as estruturas da língua para se trabalhar em sala de aula de maneira prioritária. Assim, observar e produzir textos injuntivos, tais como receita de cozinha, dá aos aprendizes a ocasião de manipular o modo imperativo e os organizadores temporais ("Primeiro, misture a farinha e o açúcar... despeje em seguida..."), enquanto os usos do pretérito imperfeito e do pretérito perfeito serão melhor abordados por um trabalho com o conto ("Ela andava tranquilamente quando um monstro surgiu...”). Os marcadores de sintaxe e um certo número de traços semânticos considerados como constitutivos do gênero podem ser elementarizados (Schneuwly \&Dolz, 2009) e trabalhados com os alunos. É o caso de todas as unidades linguísticas que participam da coesão do gênero (os tempos dos verbos que opõem a narrativa conversacional da narração; os organizadores textuais; as retomadas anafóricas, etc.). No nível da recepção, a configuração das unidades linguísticas permite a identificação do gênero, e os encadeamentos cotextuais permitem ver a organização formal e a semântica que rege a compreensão do texto. No nível da produção, elas fornecem convenções formais reguladoras da inteligibilidade do texto produzido.

Os três níveis que acabamos de exemplificar se intercalam e instituem o gênero como uma entidade de filiação múltipla entre os temas abordados, as formas linguísticas e os tipos de discurso mobilizados. O gênero, herdado e sedimentado nas tradições culturais, se transforma em permanecia. Apesar disso, além das transformações, a reflexão sobre a dinâmica entre os constitutivos genéricos é uma referência para abordar o ensino da textualidade.

\section{0 gênero textual, sim, mas no plural}

Seja plural como o universo. Fernando Pessoa

Do ponto de vista histórico, o ensino abordou durante muito tempo as particularidades dos modelos de gêneros de maneira a perpetuar as formas canônicas 
clássicas. Certos gêneros literários reinaram no ensino da literatura clássica, marginalizando outras entradas possíveis, assim como a imitação das regras explícitas de modelos epistolares foram longamente privilegiados. A modelização didática que nós propomos (Dolz \& Schneuwly, 1998) busca uma finalidade diferente. Trata-se de considerar as práticas de linguagem atuais, sem negligenciar as dimensões históricas determinadas, para tirar delas as dimensões ensináveis, tanto nos gêneros comuns, quanto nos gêneros formais e nos gêneros literários. Conhecer as características de um gênero é fundamental para escolher o que é legítimo e pertinente em relação aos objetivos escolares e às capacidades iniciais dos aprendizes de diferentes níveis. A escolarização do gênero supõe sempre uma transformação que passa necessariamente por uma integração e uma solidarização dos componentes apontados para o ensino. O modelo didático é, portanto, uma construção que permite gerar os dispositivos de ensino.

A abordagem didática pelos gêneros é uma abordagem explicitamente variacionista. Do ponto de vista linguístico, as produções textuais são distinguidas em função das situações de comunicação, considerando as particularidades enunciativas. As características discursivas e textuais específicas são situadas em relação com as condições de produção. A partir dos trabalhos dos autores de horizontes diversos como Adam (2004), Mainguenau (1998), Jauss (1978) e Bronckart, Blain, Schneuwly, Davaud e Pasquier (1985), trata-se de articular o uso das formas linguísticas aos funcionamentos discursivos. Essa perspectiva reveste uma maior importância para se abordar o ensino-aprendizagem da textualidade, pois as capacidades e as dificuldades dos aprendizes se reportam às dimensões específicas associadas ao gênero. Assim, o aluno não aprende a falar e a escrever "em geral"; ele aprende práticas de linguagem nas situações de comunicação precisas. Ele não aprende os mesmos aspectos da textualidade redigindo um soneto ou escrevendo uma dissertação. Como dissemos, os gêneros não mobilizam as mesmas configurações linguísticas. Convém, portanto, tratar estes últimos e o uso preciso das convenções pragmáticas e das unidades linguísticas como um recurso para um gênero particular. Desse ponto de vista, a vantagem de trabalhar sobre a genericidade é ressaltar seu caráter adaptável.

O desenvolvimento das capacidades de linguagem dos alunos não pode se realizar trabalhando unicamente um gênero ou uma família de gêneros. Abordar a dinâmica comunicacional entre os gêneros é indispensável. A preferência pelos gêneros narrativos de ficção (contos e álbuns) para o ensino inicial da leitura e a predominância desses gêneros na escrita ao longo do ensino limitam o trabalho focando outros atos comunicacionais específicos. O fato de se trabalhar com o conto permitirá um domínio do gênero, mas nada garante a transferência para outros 
gêneros. $\mathrm{O}$ interesse da abordagem pela diversidade dos gêneros traz, ainda, um número importante de possibilidades do ponto de vista pedagógico visando um ensino integrado. De fato, as interações verbais se regulam de maneira diversa e contrastada segundo os gêneros e é provável que a compreensão de uma explicação científica ou mesmo de um manual de instruções de um objeto possa representar obstáculos para aquele que não esteja familiarizado com esses dois gêneros. Além disso, uma didática variacionista visando o domínio escolar da diversidade dessas práticas de linguagem ganha ao propor abordagens comparatistas contrastando os textos. Trabalhar com os gêneros no plural implica estabelecer uma filiação entre os gêneros textuais, distinguir as convenções de tradição, analisar os fenômenos de relações entre os textos fonte precisos que intervém na produção (por exemplo, o resumo de uma obra literária para distinguir o resumo de um capítulo de livro didático). Trabalhar contrastando os diferentes gêneros ajuda os alunos de nível iniciante ou de nível avançado a identificar as particularidades que representam com frequência um obstáculo para avançar.

\section{Agrupar os gêneros para organizar o currículo pensando nas aprendizagens específicas}

Textos de todos os gêneros, aqui está um plural bem singular na escola. J. Dolz

Um grande problema na didática das línguas para a abordagem pelos gêneros concerne não somente os gêneros que merecem ser ensinados, mas também a organização do conjunto do trabalho no nível do curso. A organização das aprendizagens nos currículos oficiais prescritos, e naqueles efetivamente ensinados e avaliados, é importante para o direcionamento do sistema educativo. As formas de implementação na realidade cotidiana nas salas de aula mostram, independentemente das recomendações oficiais, a onipresença de certos gêneros (especialmente os gêneros narrativos ao longo da escola obrigatória e a dissertação nas formações pós-obrigatórias). Isso traz problemas tanto para abordar a diversidade textual (que, por falta de tempo ou por uma visão estreita das prioridades, pode se limitar a somente um gênero nas práticas efetivas) quanto para escolher objetos de ensino específicos (ancorados nas necessidades, nas lacunas e nas dificuldades dos alunos) permitindo espaços de aprendizagem (Marton \& Tsui, 2004). Mas, além da criação de um espaço de trabalho negociado com os alunos para trabalhar a partir de suas necessidades, os gêneros são também ferramentas para garantir transições e transferências na progressão curricular. Nas transações professor-alunos, 
o contraste entre os gêneros trabalhados anteriormente e a ativação da memória didática ocupa um papel na planificação geral do conjunto do trabalho sobre a textualidade. Além disso, as transferências possíveis das aprendizagens de um gênero para outro merecem ser examinadas, não apenas por razões práticas de gestão de tempo atribuídas à disciplina escolar. Gerenciar a progressão curricular exige, portanto, propostas sobre um agrupamento de gêneros com critérios didáticos.

Nossa proposta de agrupamento de gêneros (Dolz \& Schneuwly, 1998) se insere na tradição escolar e considera três tipos de critérios: as finalidades escolares circunscritas no ensino da expressão e da compreensão tanto no oral quanto no escrito; a retomada de diferentes tipologias discursivas existentes; as pesquisas sobre a progressão da compreensão e da produção de textos em situação escolar. Esse agrupamento, fundamentado em critérios aliados às finalidades comunicacionais, cognitivas e didáticas distingue cinco áreas sociais de comunicação:

1. Os gêneros da cultura ficcional (conto, fábula, romance, etc.);

2. Os gêneros que permitem a documentação e a memorização das ações humanas individuais e coletivas (relato de experiência vivida, relato histórico, fait divers ${ }^{4}$, etc.);

3. A discussão em torno de problemas sociais controversos (debates mediados, editorial de jornal, carta do leitor, etc.);

4. A transmissão e construção de saberes (artigo enciclopédico, apresentação oral, explicação científica, etc.);

5. As instruções e prescrições que permitem a regulação dos comportamentos (manual de instrução, receita de cozinha, etc.).

É fácil perceber as dimensões comuns no interior de cada grupo de gêneros e o interesse em tornar visível o que poderia ser transferido de um gênero a outro. Assim, quando trabalhamos os gêneros narrativos de ficção, os diferentes gêneros (uma fábula, um conto de fadas, um conto fantástico ou uma narrativa enigmática) partilham a criação de um universo de ficção, a organização cronológica das ações, a construção da intriga e o uso de um certo número de regularidades na textualização (tempos verbais, organizadores temporais, retomadas anafóricas, etc.). Por outro lado, cada gênero possui igualmente especificidades no caráter estereotipado dos personagens (por exemplo, na fábula, os animais representam características

4 Nota das tradutoras: o fait divers é um gênero típico da esfera jornalística na França e assemelha-se ao gênero notícia. No entanto, uma das diferenças importantes entre eles é que, enquanto a notícia pode referir-se fatos importantes, o fait divers restringe-se a notícias sem importância. Em razão dessas diferenças, optamos por não traduzir o termo. 
morais), na representação da narração, a ordem e o objetivo da narrativa (por exemplo, na narrativa enigmática, a reconstrução de trás para frente da história do crime pelas sucessivas descobertas do detetive).

A porosidade dos gêneros literários (Reuter, 1990; Denizot, 2008) atravessa o conjunto dos agrupamentos que acabamos de apresentar. As restrições comunicativas dos gêneros pragmáticos da vida cotidiana estabelecem uma relação de conformidade com o horizonte de expectativa (Jauss, 1978) enquanto que os gêneros literários, em função do contexto de produção sócio-histórico, podem se inscrever em uma lógica de adesão ou de ruptura, ou mesmo entre essas duas lógicas. A singularidade desempenha um papel particular em uma estética moderna.

Do ponto de vista didático, a essas cinco famílias de gêneros que compartilham uma parte de traços genéricos, há de se questionar o poético, tanto através dos gêneros canônicos, onde ele é reconhecido, mas também, potencialmente, através da pesquisa do que se poderia relevar de poético nos gêneros que não são reconhecidos a priori como tais (tanto os textos em prosa quanto aqueles em versos). De fato, a poesia - difícil de definir - é uma prática muito diversa que ultrapassa os gêneros e que nos convida a questioná-los. Podemos, por exemplo, encontrar um poema em prosa relacionado a um fait divers (o poema Oklahoma de Blaise Cendrars, por exemplo), um aforismo argumentativo de René Char, ou ainda as fábulas de La Fontaine, textos poéticos que se inscrevem igualmente em um gênero narrativo. A poesia acolhe uma diversidade de gêneros que, além da forma em versos, merece ser considerada no ensino.

\section{Avaliar o texto do aluno em uma perspectiva genérica}

Os ovos que comemos em pares parecem gêmeos ao passo que eles não são nem mesmo primos distantes.

Gómez de la Serna

Uma primeira tensão que nós detectamos no ensino pelos gêneros é a da avaliação da produção dos alunos com um foco nas dimensões singulares ou transversais, avaliação que considera mais ou menos as dimensões genéricas. A recepção de textos dos alunos pelo professor, os gestos de correção e de comentários avaliativos nas provas, assim como a utilização de fichas de avaliação para facilitar a transferência para outras produções serão examinadas na sequência a fim de mostras a dialética do texto-gênero nas práticas de ensino. 
Linha D'Água (Online), São Paulo, v. 28, n. 2, p. 5-25, dez 2015

\section{a) A recepção das produções singulares dos alunos}

Um gênero de longa tradição recai na infância a cada nova produção.

J.Dolz

Nós constatamos, analisando as práticas sociais de produção escrita, que a recepção, pelos professores, dos textos produzidos pelos alunos se efetua de maneira diversa. Às vezes, os professores leem e avaliam os textos do ponto de vista das dimensões que atravessam a escrita em geral. A atenção se concentra então na ortografia, no léxico, no domínio da conjugação, no estilo pessoal e, para os menores, no domínio - ou não - do código. O extremo oposto é o do ensino que aplica uma ficha de avaliação nos componentes padrão do gênero, às vezes em detrimento da pertinência da escrita singular do jovem aprendiz. Enfim, alguns professores recebem ainda os textos dos alunos como atos comunicacionais, individuais, originais, criativos e específicos. Nesse último caso, as dimensões genéricas são mobilizadas de maneira muito incipiente ou até mesmo nula.

É evidente que no quadro da abordagem comunicativa, os textos singulares do aluno merecem um tratamento enquanto tal. Nada substitui um diálogo com o aluno sobre o sentido que ele desejou dar a seu texto. Entretanto, se as dimensões genéricas não são abordadas, o aluno perde a possibilidade de uma referência às convenções de uso. Sem uma leitura que tente compreender o sentido do texto do aluno e as significações que ele atribui às formulações atípicas, arriscamos uma ruptura na situação de comunicação e na interpretação dos fatores pragmáticos ou intencionais que explicam essas produções singulares. Além disso, as produções verdadeiramente originais que subvertem as convenções correm o risco de ser desvalorizadas por uma visão tecnicista, onde a expectativa visa apenas um produto padronizado. Da mesma maneira, as dimensões transversais do texto devem, em um dado momento, serem integradas à escrita, mas não exclusivamente. Nós sabemos que a sobrecarga cognitiva na escrita de um texto pode levar a negligenciar as dimensões sintáticas, mas estas podem ser tratadas em diferentes momentos. A escrita e a revisão do texto implicam sempre em um trabalho sobre essas dimensões.

No que uma recepção do texto ganharia por ser abordada pelas dimensões genéricas? $\mathrm{O}$ olhar sobre a genericidade supõe, no ensino, ir além da produção singular para projetar o aluno em um olhar sobre as práticas de referência, nas adaptações ao leitor (que acolhe sempre o texto com um horizonte de expectativa genérico), e sobretudo para refletir sobre todos os componentes do gênero, nas suas potencialidades para produções escritas futuras. A relação ao texto escrito na escola tem sempre um objetivo de aprendizagem. É nesse sentido concreto que o modelo didático do gênero fornece um benefício ao trabalho do professor. 
A abordagem do ensino pelos gêneros apresenta uma tensão dupla, tanto com as dimensões transversais quanto com as dimensões singulares, que são na realidade complementares, e que não podem ser negligenciadas. Compreender o que quis dizer o aluno, torná-lo atento ao sistema de regras da língua, à pertinência do léxico utilizado etc., não está em contradição com a mobilização de todos esses elementos na perspectiva dos gêneros. O problema, para o professor, reside na maneira de articular esse triplo olhar. $\mathrm{O}$ gênero não pode negligenciar o texto. Entretanto, um trabalho sobre os textos singulares que não leva em conta as ferramentas do gênero limita as aprendizagens dos alunos.

As tarefas propostas nos meios de ensino e pelos professores podem evocar, ou não, um gênero, e propõem geralmente situações de comunicação que dirigem o aluno para produções singulares. Essas tarefas não são sempre fáceis de interpretar, e constatamos obstáculos na escrita associados às situações propostas (Vuillet, Tobola-Couchepin, Mabillard, \& Dolz, 2012). Às vezes a ficcionalização da situação de comunicação está bastante distante das práticas de referência do gênero, pois esse é necessariamente didatizados pelos meios de ensino ou pelo professor. A instrução abaixo, proposta por um professor, mostra como se articula um gênero argumentativo "resposta à carta dos leitores" fornecido como título escrito do texto concreto a ser realizado. A tarefa é formulada da seguinte maneira:

"Leia atentamente o texto enviado por Anne e responda-lhe (em forma de carta) dando sua opinião".

Tenho trinta anos e gosto muito de ler a seção "Correio dos leitores". Sou mãe de um garoto de vai comemorar seus 10 anos e não sei qual presente dar para o seu aniversário. Meu filho gostaria muito de ganhar um console de videogame, mas eu, eu preferiria comprar um skate porque não quero que ele passe o dia dentro de casa, em frente à televisão. Vocês acham que eu tenho razão?

Anne.

O gênero anunciado para os alunos de 8-9 anos é uma resposta à carta do leitor, mas os alunos seguem normalmente a instrução escrevendo uma carta para Anne, a mãe de um aluno, sem se dirigir ao público do jornal juvenil, e às vezes, sem uma perspectiva argumentativa. Eles se limitam a exprimir sua posição pessoal sobre o presente a oferecer ao filho de Anne, ou a dar sua opinião geral sobre o objeto console de videogame. A tarefa apresenta diferenças com as cartas dos leitores da imprensa escrita (existe uma dupla transposição: na adaptação à imprensa para os jovens e na transformação pelo professor). E os textos escritos pelos jovens alunos iniciantes estão distantes dos artigos das cartas dos leitores de um jornal. 
Um segundo exemplo tirado de um livro didático oficial na Suíça (Mon manuel de français, $6^{\mathrm{e}}$ ) ilustra nosso propósito. Após a leitura de um curto artigo de jornal sobre a erupção de um vulcão na ilha da Reunião (um fait divers), o livro formula a seguinte instrução: "Escreva um pequeno texto para esclarecer o que você sabe sobre este fenômeno natural. Se desejar, você pode adicionar um desenho ao texto." (p.48). Nenhum modelo do gênero visado é fornecido antes dessa escrita. Após a realização de uma maquete para simular uma erupção vulcânica (p.52-53), a nova tarefa de escrita proposta é a seguinte: "A partir da experiência realizada, escreva uma ficha de sintese para descrever e explicar o fenômeno analisado tendo o cuidado de apresentar a experiência e explicar o resultado." (p.59). Passamos de um gênero injuntivo (manual de instrução da maquete) a um gênero explicativo. Em um objetivo da escrita a serviço do ensino de ciências, a sequência proposta por esse livro aborda um tema desenvolvido em uma diversidade de gêneros, e passa de um gênero a outro sem explicitar as transformações esperadas na escrita, nem o objetivo nem o destinatário.

Por meio desses dois exemplos, vemos que as instruções fornecidas combinam elementos que visam a produção de um ou vários textos com uma referência mais ou menos direta aos gêneros aos quais pertencem. A avaliação e a correção das produções textuais devem levar em consideração esses elementos, não somente para avaliar a capacidade de adaptação do aluno à tarefa, mas igualmente para detectar possíveis obstáculos associados à compreensão e ao tratamento dessa tarefa.

Dois gestos do professor devem ser levados em consideração para especificar a relação entre texto e gênero. Acabamos de examinar o gesto de implementação de situações de produção textual que faz majoritariamente parte da criação de dispositivos de ensino. Vamos agora nos voltar para os gestos de avaliação, dentre os quais a regulação do texto produzido pelo diálogo professor-aluno, a correção e comentários avaliativos dos textos.

\section{b) Regular, corrigir e comentar e avaliar os textos dos alunos}

Há algo a dizer a favor da excę̧ão desde que ela não queira nunca se tornar a regra.

A heterogeneidade dos textos produzidos pelos alunos, a partir de uma mesma instrução, pode ser muito importante. A proximidade ou a distancia dos textos empíricos considerados como pertencendo a um gênero nas práticas sociais é muito variável, principalmente nos alunos mais novos. Antes de corrigir, de comentar e 
de avaliar os textos dos alunos, os professores experientes que demonstram interesse pela expressão dos alunos os questionam a fim de permitir-lhes clarificar o que quiseram dizer. Esse diálogo constitui, para nós, um gesto de regulação que cruza a leitura e a observação do texto escrito com uma atividade metalinguageira por parte do aluno, permitindo-lhe retornar ao que escreveu explicitando sua intencionalidade. $\mathrm{O}$ simples fato de ler em voz alta o texto produzido, ou de reler-se a si próprio, pode levar o aluno a transformar diretamente as formulações ou a fazer comentários ou complementos de informação. O aluno percebe se o texto foi recebido e compreendido. Entretanto, nada substitui as questões sobre a significação das formulações difíceis de acompanhar, sobre os conteúdos temáticos e sobre a forma do texto. Observamos, nas nossas pesquisas sobre as práticas de ensino, que essas questões ganham ao ser formuladas utilizando uma terminologia explícita sobre as convenções genéricas, o que contribui para desenvolver os conhecimentos sobre o gênero e o horizonte de expectativa social a atingir. $O$ benefício visado pela didática dos gêneros é um deslocamento e um reconhecimento das convenções discursivas gerais. Apenas com o gesto de regulação quando da recepção do texto produzido, o professor contribui para um ensino explícito que beneficia todos os alunos, principalmente os alunos em dificuldade. A singularidade pode assim ser acolhida lembrando as convenções a respeitar, a dificuldade em se situar fora de todas as normas genérica, mas valorizando a individualização e a originalidade que podem já estar presentes desde a mais tenra idade.

A prática da correção dos erros dos textos dos alunos constitui uma forma de intervenção que tem uma longa história. Algumas práticas de ensino se limitam à correção e ao comentário avaliativo dos textos devolvidos aos alunos. No passado, a instituição prescrevia um retorno dessas intervenções sobre os textos, e os inspetores, nas visitas de classe, verificavam a natureza desses retornos. Nas práticas que observamos, os gestos de correção e de comentários avaliativos dos textos merecem ser diferenciados. Às vezes o professor corrige em vermelho os erros ortográficos, ou, ao contrário, sublinha em verde as partes que não apresentam erros, e devolve o texto corrigido ao aluno para que ele possa identificar o que é aperfeiçoável. Nas práticas comuns, a atenção dada às dimensões transversais (ortografia, sintaxe, conjugação e escolha do vocabulário) domina amplamente. Em contrapartida, no gesto de comentários avaliativos dos textos, as questões e as apreciações se ampliam e tratam igualmente da significação de uma formulação, da categorização dos erros, da planificação do texto, do respeito às convenções genéricas e de estilo. As finalidades das observações sobre a singularidade do texto, sobre o respeito das convenções ou ainda sobre o código linguístico não são idênticas. A vantagem dos comentários avaliativos sobre as convenções e as subversões discursivas é de 
permitir ao aluno situar-se em relação ao sistema de normas coletivas explícitas e apropriar-se do gênero. Entretanto existem dois tipos de alteridade na escrita do aluno, aquela saída do desconhecimento das convenções coletivas e aquela motivada pela busca de individualização e de originalidade. Os dois devem ser diferenciados, mas seu tratamento exige, nos dois casos, levar em consideração as convenções genéricas como referência.

\section{c) Para uma transferência para outros textos pertencendo ao gênero}

Somente no vocabulário dos costureiros moldes é sinônimo de modelo. De Aymond D'Alost

Enfim, os gestos de avaliação (tanto de correção quanto de comentários avaliativos) podem ter um objetivo de transferência. De fato, uma ficha de avaliação construída com os alunos pode apontar elementos da tarefa precisa para produzir um texto singular ou examinar os componentes do gênero. $O$ desvio da utilização desse tipo de ferramenta, inicialmente como lembrete da produção para o aluno, em seguida como ficha de avaliação para o professor é o fato de que os alunos podem aplicá-los mecanicamente e chegar a resultados muito semelhantes, como já mostrado, excessivamente estandardizados. No entanto, o objetivo é outro, pois é para reter e interiorizar de maneira explícita as dimensões que não podem ser negligenciadas. Aqui, a tentativa é de procurar itens e critérios que possam ser transferidos a outros textos pertencentes à mesma galáxia de gêneros.

Examinamos as tensões na avaliação das produções escritas dos alunos e não temos espaço suficiente para estudar as tensões no nível da avaliação da compreensão. A construção do sentido quando da escuta de uma gravação oral ou da leitura de um texto escrito se dá sempre a partir de um texto singular. Entretanto, a orientação para o horizonte de expectativa formulando tarefas relativas aos componentes do gênero permite uma centralidade nas dimensões que são frequentemente negligenciadas pelo aluno. Assim como para a avaliação da produção, é conveniente explorar a complementaridade entre o olhar direto sobre o texto e uma mediação pela ferramenta gênero. Tanto em produção como em compreensão, é importante evitar os desvios de uma possível reificação de um olhar exclusivamente singular ou de um questionamento que se referiria apenas sobre as dimensões associadas às regularidades do gênero. A avaliação das capacidades e dos obstáculos do aluno implica esse duplo olhar.

5 Nota das tradutoras: utilizamos "molde" para dizer "patron". 
Linha D'Água (Online), São Paulo, v. 28, n. 2, p. 5-25, dez 2015

\section{Intervir no gênero ou no texto?}

Pensamentos sem conteúdos são vazios, intuições sem conceitos, cegas.

Kant

Não existe uma entrada única no ensino da escrita. Desenvolver progressivamente o domínio da diversidade das práticas de escrita pode ser feito de maneiras muito diferentes. Em uma visão da escrita como processo de produção, e não somente como simples produto final, as atualizações dos rascunhos de escritores e de alunos (Bucheton, 1995 ; Fabre-Cols, 2002), como assinalado na parte precedente, toma toda sua importância. Entretanto, as abordagens desse ensino podem ser muito diversas. Barré-de-Miniac (2000) evoca as seguintes entradas: a apropriação do código e das funções da escrita nas primeiras etapas da escolaridade; o trabalho em projetos de escrita; os procedimentos de escrita e de reescrita a partir de rascunhos, as interações leitura-escrita; a escrita a serviço da aprendizagem de outras disciplinas; as intervenções centradas no ensino da ortografia; as novas tecnologias a serviço da escrita; os ateliês de escrita criativa; e a abordagem que estamos aqui analisando, ou seja, a caracterização e a modelização didática dos gêneros textuais para o ensino. Nenhuma dessas entradas é exclusiva mesmo se a importância dada a cada uma possa ser muito diferente. Vamos mostrar como essas diferentes entradas podem se entrecruzar nas intervenções dos professores, buscando ressaltar o caráter integrador da abordagem por gêneros.

Nas intervenções sobre a construção do sentido de um texto, a orientação prévia, os modos de leitura e a compreensão local ou global do texto enquanto objeto social implicam também a possibilidade de uma perspectiva pelos gêneros. A intenção do autor, a forma do texto e os conteúdos temáticos dependem do gênero ao qual o texto singular pertence. Os dispositivos transversais mobilizados sistematicamente pelos professores quando do treinamento para a leitura são os seguintes: questionamento sobre o sentido geral do texto e sobre os significados das diferentes partes, o trabalho sobre o vocabulário novo presente no texto, e junto aos mais novos - as atividades que visam ao domínio do código necessário à decodificação. Ao lado dessas atividades relativamente clássicas, começamos a ver aparecer categorias de atividades escolares que incidem sobre gêneros textuais ou literários particulares (Aeby Daghé, 2014). As fichas que acompanham a leitura de livros juvenis apresentam uma diversidade dessas atividades. A observação do ensino explícito da leitura durante a escolarização obrigatória (Thévenaz-Christen, 2014) mostra a existência de dois modelos de concepção da leitura. O primeiro, modelo inferencial de tratamento da leitura, concebe a leitura como uma atividade 
Linha D’Água (Online), São Paulo, v. 28, n. 2, p. 5-25, dez 2015

de resolução de problemas, enquanto o segundo modelo interpretativo, é instrumentalizado por um modelo de textos. Esse último se constrói à partir de um horizonte de expectativa forjado pelos projetos de leitura e os gêneros discursivos e textuais.

\section{a) $O$ trabalho sobre a textualidade transversal e singular}

\section{Tudo que é puro de fato de estilo é elaborado.}

Gombrowicz

Acompanhar a aprendizagem da produção escrita supõe intervir sobre os textos seja diretamente, seja graças a atividades soltas, seja ainda em uma sequência que articula as diferentes atividades. $\mathrm{O}$ conjunto de atividades escolares sobre a ortografia presente nos maios de ensino é muito importante. Ela trata de todos os componentes do plurisistema ortográfico. Frequentemente, esses componentes são trabalhados com a ajuda de fichas de exercícios para criar automatismos, ou associados à produção de um texto particular (Allal, Bétrix Köhler, Rieben, Rouiller Barbey, Saada-Robert, \& Wegmuller, 2001). Da mesma maneira, para a entrada no mundo da escrita, Martinet, Cèbe e Pelgrims (2015) propõem uma ferramenta didática centrada na aprendizagem explícita dos procedimentos requeridos para copiar rapidamente e de maneira automática, e estratégias de memorização da ortografia. Por outro lado, as possibilidades de intervir sobre os fenômenos de textualização em todos os níveis são muito importantes. Os exercícios sobre as estruturas sintáticas, sobre os funcionamentos dos tempos do verbo, ou ainda sobre a coesão e a coerência do texto podem ser feitos sem a necessidade de uma entrada pelos gêneros. As vantagens de uma intervenção integrada ao gênero, como já dissemos, concernem o sentido do trabalho junto aos alunos (evitar o desvio tecnicista) e a possibilidade de integrar e explicitar a relação entre os fenômenos transversais e de textualização abordados no quadro das práticas sociais da escrita. Apenas para o tratamento de um problema transversal, treinar por meio de exercícios do tipo drills (estruturais) não seria suficiente. É preciso igualmente assegurar que a aprendizagem da ortografia possa ser integrada na produção de um texto particular. A precisão do gênero e das condições de produção acarreta consequências, ao menos em termos de representações, para os escritores. Os alunos podem assim identificar a importância de mostrar um bom domínio da ortografia para adaptar-se a seus destinatários. Por exemplo, se os alunos estão trabalhando sobre uma carta de solicitação dirigida às autoridades, ou sobre uma carta aos leitores, publicada no jornal escolar, eles percebem a importância, para o local de publicação como 
para sua imagem, do domínio da ortografia. Entretanto, no que diz respeito aos fenômenos de textualização, se queremos trabalhar sobre um verdadeiro domínio do funcionamento dos tempos verbais ou da conexão do texto com organizadores textuais, ou ainda sobre as retomadas anafóricas, para citar apenas três mecanismos particulares, as unidades linguísticas mobilizadas serão diferentes, e aqui, a abordagem por gêneros nos parece particularmente pertinente. Em termos de progressão curricular, todas as nossas observações mostram um trabalho cada vez mais afinado sobre o "estilo" nos níveis superiores de ensino. Mas o estilo não se refere apenas à organização dos motivos estéticos individuais de um autor. Existe uma estilística pragmática associada aos gêneros textuais, às determinações formais que os estruturam e ás configurações de unidades linguísticas que os compõem. Seguindo Adam (1997), o estilo merece ser reinterpretado no seio de uma teoria do texto que, para nós, se aplica sobretudo aos gêneros textuais e às convenções que os caracterizam.

\section{b) A elementarização das dimensões genéricas}

A chuva não afoga as pulgas. Gómez de la Serna

A abordagem por gêneros procede por um movimento que vai do complexo ao simples, para retornar ao complexo. O gesto de elementarização dos componentes se dá em função de um exame das capacidades iniciais dos alunos ou das novidades que nunca foram abordadas. Apontar essas dimensões permite focalizar explicitamente a atenção do aluno sobre o que ele ainda não domina, treinar sobre um mecanismo de textualização novo. Como defendemos anteriormente (Dolz \& Abouzaïd, 2015), as atividades e os exercícios escolares ajudam a transformar as capacidades dos alunos a condição de preencher uma série de condições e ultrapassar a lógica da repetição para criar automatismos. Simplesmente, uma vez que o aluno trabalha sobre essas dimensões, é necessário reinvesti-las em um texto completo lembrando o papel do mecanismo de textualização estudado em um gênero particular trabalhado. Retomemos o exemplo do uso do passado/pretérito imperfeito/simples/mais que perfeito na escrita de uma narrativa de enigma. Os exercícios para marcar o primeiro plano e o plano de fundo da narrativa (figura e fundo) assim como os flash-backs no mais que perfeito podem ser observados nas narrativas de enigma e trabalhados em seguida em ateliês (ou módulos) para crias os efeitos de sentido esperados. $\mathrm{Na}$ pesquisa conduzida atualmente sobre os gestos do professor sobre a produção escrita de uma carta aos leitores, pudemos constatar 
o efeito massivo, tanto nos alunos em dificuldade como nos alunos avançados, do trabalho sobre o desenvolvimento e a hierarquização dos argumentos combinando atividades sobre a elaboração de argumentos e a utilização de organizadores textuais e enumerativos (primeiramente, então, em seguida, para concluir). A elementarização e o treinamento transformam as produções dos alunos iniciantes escritores de 8-9 anos.

\section{c) A articulação gênero-łexto}

L'inconvénient du mot union au pluriel est que ça fait des unions. ${ }^{6}$
Vicent Roca

Quaisquer que sejam os conteúdos e a forma do texto a escrever, convém articular a reflexão sobre o texto singular e as convenções genéricas. Nos jovens alunos, constatamos que o trabalho sobre uma situação de comunicação particular permite ao aluno, progressivamente, entrar em considerações genéricas mais gerais. As convenções genéricas mais abstratas são difíceis de assimilar para os alunos mais novos. No ensino precoce da produção escrita, eles têm necessidade de tarefas e atividades que lhes permitam antecipar muito claramente o texto a ser escrito. No caso particular da escrita de uma carta ao leitor, alguns professores trabalham sobre várias controvérsias (ir ou não de bicicleta para a escola, obrigação ou não dos deveres escolares, escolha de um presente para um aniversário etc.). $\mathrm{O}$ simples fato de passar de um tema a outro e de elaborar argumentos a propósito de várias controvérsias supõe uma sobrecarga, e, no final, os progressos dos alunos não são tão visíveis. Ao contrário, se a produção inicial, o trabalho em ateliê e a produção final são sobre o mesmo texto, há o risco de aborrecer o aluno pela repetição, mas, sobretudo de não projetar a aprendizagem sobre questões mais gerais podendo ser transferidas de um texto a outro. Estamos analisando as transcrições das interações em aulas, de diferentes professores, para ver, muito concretamente, como o professor alterna as intervenções sobre os textos efetivamente produzidos pelos alunos - avançados ou com dificuldades - a fim de melhor compreender o interesse e as formas concretas que toma essa articulação. No outro extremo do sistema educativo junto aos alunos do ensino médio ${ }^{7}$ que já dominam as principais convenções de um gênero textual, é possível trabalhar a criatividade e a

6 Nota das tradutoras: o autor faz aqui um jogo de palavras, pois ao ler des unions no plural temos o mesmo som de désunion - desunião. Daí a frase "o inconveniente da palavra união no plural é que dá des unions".

7 Nota das tradutoras: post-obligatoire no original. 
Linha D’Água (Online), São Paulo, v. 28, n. 2, p. 5-25, dez 2015

singularidade de uma maneira diferente. Lá, os conhecimentos sobre o gênero constituem uma base para o desenvolvimento da escrita.

\section{Conclusão}

A título de conclusão, a abordagem por gêneros é uma abordagem que não se pretende exclusiva. Os gêneros textuais são uma ferramenta didática poderosa que permite um movimento de generalização para as convenções que os constituem. Tentamos, ao longo dessa contribuição, mostrar as tensões existentes no nível da avaliação das capacidades dos alunos, coo no nível das intervenções dos professores, entre os textos singulares e os gêneros. É verdade que nos dois extremos, podemos perceber, pela observação das práticas, riscos de reificação. Podemos também ter um desvio tecnicista pela força da própria ferramenta didática gênero, como uma impossibilidade de entrar no social se tudo for focado no individual e singular. A dialética proposta pela abordagem dos gêneros nunca pretendeu excluir a singularidade, a criatividade e a originalidade, que têm todo seu lugar no desenvolvimento linguageiro na escola. Dito isso, precisamos saber mais sobre a maneira de ultrapassar, tanto pelos professores como pelos alunos, as tensões evocadas. É por isso que continuamos nossas pesquisas sobre as práticas de ensino. Na didática das línguas que defendemos, essas tensões, longe de serem banidas, merecem ser conhecidas e exploradas no desenvolvimento profissional dos professores e no desenvolvimento linguageiro dos alunos.

\section{Referências}

Adam,J.-M.(1997). Le style dans la langue. Une reconception de la stylistique. Lausanne : Delachaux \& Niestlé.

Adam, J.-M. (2004). Linguistique textuelle. Des genres de discours aux textes. Paris : Nathan.

Aeby Daghé, S. (2014). Candide, la fée carabine et les autres. Vers un modèle didactique de la lecture littéraire. Berne : Lang.

Allal, L., Bétrix Köhler, D., Rieben, L., Rouiller Barbey, Y., Saada-Robert, M. et Wegmuller, E. (2001). Apprendre l'orthographe en produisant des textes. Fribourg : Éditions universitaires.

Audigier, F. Crahay, M. Dolz,J.(2006). Curriculum, enseignement etpilotage. Bruxelles : DeBoeck. 
Linha D’Água (Online), São Paulo, v. 28, n. 2, p. 5-25, dez 2015

Bakhtine, M. (1984). Esthétique de la création verbale. Paris : Gallimard.

Barré-de-Miniac, Ch. (2000). Le rapport à l'écriture : aspects théoriques et didactique. Villeneuve d'Asq : PU du Septentrion.

Bronckart, J.-P., Blain, B., Schneuwly, B., Davaud, C. \& Pasquier, A. (1985). Le fonctionnement des discours. Neuchâtel : Delachaux et Niestlé.

Bronckart, J.-P. (1996). Activité langagière, textes et discours. Pour un interactionnisme socio-discursif. Neuchâtel : Delachaux et Niestlé.

Bucheton, D. (1995). Ecriture, réécriture, récits d’adolescents. Berne: Lang.

Canvat, K. (1986). Types de textes et genres textuels. Problématiques et enjeux. Enjeux, 37/38, 5-29.

Couté, B., Durand, V., Pradeau, J. \& Rondelli, F. (2004). Mon manuel de français, Paris: Retz.

Denizot, N. (2008). Genres littéraires et genres textuels en classe de français. Scolarisation, construction, fonctions et usages des genres dans la discipline français. Thèse de doctorat en Sciences de l'éducation. Université de Lille.

Dolz, J. \& Abouzaïd, M. (2015). La place de l'exercice sur la production orale et écrite dans l'enseignement et dans la formation, Lettre de l'AIRDF, 57, 11-18.

Dolz, J. \& Schneuwly, B. (1998). Pour un enseignement de l'oral. Paris: ESF.

Fabre-Cols, C. (2002). Réécrire à l'école et au collège. De l'analyse des brouillons à l'écriture accompagnée, Paris: ESF.

Jauss, H. R. (1978). Pour une esthétique de la réception, Paris: Gallimard.

Mainguenau, D. (1998). Analyser les textes de communication. Paris: Dunod.

Martinet, C., Cèbe, S. \& Pelgrims, G. (2015). SCRIPTUM : un outil pour apprendre à écrire: copier et orthographier (classes ordinaires et spécialisées). Paris: Hatiers. 
Linha D'Água (Online), São Paulo, v. 28, n. 2, p. 5-25, dez 2015

Marton, F. \& Tsui, A.B.M. (2004). Classroom Discourse and the Space of Learning. London: Lawrence Erlbaum Associates.

Schneuwly, B. \& Cordeiro, G. S. (à paraître). Le genre de texte comme objet d'enseignement Comparaison de deux approches didactiques, in G. Sales Cordeiro \& D. Vrydaghs [Ed.], Les genres dans l'enseignement du français : un objet oulet un outil didactique? Namur: PU Namur.

Reuter, Y. (1990). Définir les biens littéraires ? Pratiques, 67, 5-14.

Schneuwly, B. (1994). «Genres et types de discours. Considérations psychologiques et ontogénétiques ", in Y. Reuter [Ed.], Les interactions lecture-écriture (pp. 245-263). Bern: Lang.

Schneuwly, B. \& Dolz, J. (2009). Des objets enseignés en classe de français. Rennes: PUR.

Schneuwly, B. \& Dolz, J. (2004). Gêneros orais e escritos na escola. Campinas: Mercado de Letras.

Thévenaz-Christen, T. (2014). La lecture enseignée au fil de l'école obligatoire. L'exemple genervois. Namur: Diptyque, PU Namur.

Volochinov, V. (2010). Marxisme et philosophie du langage. Limoges, Lambert-Lucas, [Edition originale en russe : 1929].

Vuillet, Y., Tobola-Couchepin, C., Mabillard, J.-P. \& Dolz, J. (2012). Dédoublement du genre et opérations de fictionnalisation : Faire « comme si c'était vrai » ou divers visages de l'altération didactique ? Éducation et didactique, 6/2, 87-100.

Vygotski, L. S. (1934/1995). Pensée et langage. Paris : Messidor.

\section{Tradução de:}

Emily Caroline da Silva -

Universidade de São Paulo, São Paulo, SP, Brasil .

Flavia Fazion

Universidade de São Paulo, São Paulo, SP, Brasil . 